\title{
Sexual Vampires: Myths and Motivations
}

\author{
Suzanne Carré \\ Hesperus \\ Director of Current and Longitudinal Analyses of the Vampire-Identifying Subculture \\ (CLAVIS) \\ Deacon Gray \\ Founding member of the Boise BDSM Community (Idaho)
}

\section{Introduction}

The study of "real vampires" has attracted considerable recent academic interest (Browning, 2015a, 2015b; Laycock, 2009a, 2009b, 2010, 2016; Williams, 2008, 2009, 2013; Williams \& Browning, 2016; Williams \& Prior, 2015) in a condition which said vampires claim exists not by choice (Laycock, 2010; Williams \& Prior, 2015). Thus, being a vampire is considered among academics and professionals as an alternative identity (Laycock, 2010; Williams \& Prior, 2015). An individual self-identifying as a "real vampire" believes they need to consume either blood or "energy" (usually of human origin) in order to maintain their well-being (Laycock, 2009a, 2010; Williams \& Prior, 2015), where the term "vampire" refers to the preferred feeding process (Williams \& Prior, 2015). While the focus of research has largely been on vampires requiring blood, called "sanguinarians" (Laycock, 2009a; Williams \& Prior, 2015), whose consumption of human blood is considered in mainstream culture to be socially unacceptable (Browning, 2015a), those who feed on energy, called "psychic vampires" (Laycock, 2009a), in fact use a variety of feeding methods, including sex (Browning, 2015a).

In this article, we present the results of a survey conducted to study a lesser known minority of real vampires called "sexual vampires" who claim to use sexual activity to feed (Browning, 2015a, 2015b). Apart from being mentioned briefly in literature (Browning, 2015a, 2015b; Laycock, 2009a), there is nothing reported about sexual vampires, thus this represents the first study of this particular vampire identity. Sexual vampires are sometimes called Eros vampires, a term coined by one of us (DG), and Tantric vampires (Belanger, 2004) on account of their practicing "tantric sex." One of us (DG) defines sexual vampires as: "any vampire, regardless of their feeding needs, who actively requires some sort of sexual stimuli, either produced or evoked, in order to make the act of feeding of value." In the present study, we explore sexual motivation and necessity for sex in the feeding needs of sexual vampires. Examining sexual feeding in a sex-positive manner (Williams et al. 2013, 2015) might help sexual vampires to meet their unique needs by finding donors. 
At present sexual vampires are misunderstood within the real vampire community, where it is expected they ought to enjoy some measure of acceptance. Sexual vampires often remain silent regarding their feeding, yet in private online groups, many engage in open and constructive discussions concerning their sexual practices. Communication with other types of vampires often seems hindered by a lack of information. Using collected data (including interviews), we examine assumptions surrounding sexual vampires and suggest that applying a sex-positive approach could assist this sexual minority by helping younger vampires gain assistance from the broader vampire community without fear of prejudice.

The process of vampires revealing their alternative identities (vampirism) to others has been termed "coming out of the coffin" (Williams \& Prior, 2015). Within their intimate relationships, vampires appear to be open about their alternative practices. Even so, there is a general fear by vampires to discuss their condition with health professionals, and sexual vampires have been warned against doing so (Gray, 2016, para. 12), given the possible disapproval of their "deviant" sexual activity (Aaron, 2016). A sex-positive approach among health professionals could empower sexual vampires when seeking treatment for health-related issues.

\section{Method}

An online survey was posted in various Facebook groups frequented by real vampires. The target audiences were both self-identified sexual vampires and those vampires who supplement their feeding with sexual activity or sexual energy in some way. In this study a majority of the vampire-participants were chronic and reported suffering from their vampiric condition for 16 or more years. We asked 46 questions divided into three main categories: relationships (romantic and with donors), feeding practices, and participation in BDSM (bondage and discipline, dominance and submission, and sadomasochism). Our convenience sample yielded 63 responses, but we only used 40 because the answers to 23 forms were deemed either inconsistent or reflecting deliberately abusive responses. While the sexual nature of the questions might account for a high level of apparently deliberate inaccuracy, much of the discarded data also reflected generally negative attitudes towards sexual vampires within the broader vampire community.

Upon review of the responses to our basic questions, we decided that trying to better understand the mechanisms of sexual feeding and the practice of BDSM among many vampires necessitated a qualitative follow-up exploration. Subsequently, some sexual vampires were interviewed to provide more details where the original survey failed to provide sufficiently detailed information. We approached 14 vampires to share more information via email or private chats, and we estimate that at least 35 vampires engaged in discussion groups on Facebook to provide additional information on feeding techniques. This second survey was conducted anonymously and we did not ask all interviewees if they answered our original survey. In the process of analyzing these data, 
the issues particular to sexual vampires - a range of sexual myths and assumptions became apparent. Our findings are important given that a sex-positive approach might lessen the preconceptions surrounding sexual vampires.

\section{Participants}

Participants reported a wide range of gender identities, which included 19 females, 15 males, three genderfluid, one agender, one trans-male, and one gender nonconforming. Sexual orientation was likewise diverse within this group, including 14 pansexual/omnisexual, 11 heterosexual, seven bisexual/bicurious, four gay/lesbian, two asexual, and one gender-queer; one female-identified respondent failed to answer the question. In private group discussions, it has been observed that sexual vampires may be more likely to present non-traditional sexual orientations compared to other vampire types (Williams \& Prior, 2015).

\section{Results}

\section{Sexual Feeding}

As noted earlier, vampires believe they are born with vampirism, a condition similar to sexual orientation (Williams \& Prior, 2015). Feeding methods are often used by researchers to classify vampires (Laycock, 2009a), i.e., blood (sang), energy (psi), and sexual (tantric) (Browning, 2015a). However, in this study most vampires reported using more than one feeding method, and not all methods were mutually exclusive. Some of the vampires we interviewed implied their feeding practice is, like their vampirism, not a choice at all, so we propose the term "feeding orientation" to suggest the lack of preference to modify feeding activities (Atlanta Vampire Alliance, 2007, p. 31). We did not investigate whether sexual vampires can alter their feeding methods to exclude sex and thereby use sang or psi feeding. However, a positive sexuality approach suggests that vampires' sexuality is unique, and can thus empower vampires to meet their preferred energy needs without having to conform.

Findings show that participants practiced diverse forms of sexual energy feeding methods. "Ambient feeding" (Browning, 2015a) involves absorbing energy that surrounds people, either generated by flirtations or indirectly from excess energy given off by patrons of clubs or during BDSM scenes, and it requires the vampire to be in proximity of the donor(s). Sexual energy may also be generated remotely, either by phone or on internet chat sessions. Most of the vampires we surveyed claimed to derive sexual energy remotely. Of these, a high proportion had at least one regular donor, but it was more common for the vampire to have more than one remote donor. As with ambient feeding, flirtations were necessary to either establish or enhance the sexual feed, and intimacy with their remote donor seemed necessary.

"Contact feeding" (Browning, 2015a) occurs when physically touching the donor, but does not necessarily involve invasive contact. Cuddling, which was described as 
being more emotionally intense with a vampire, is a common practice. More vampires in our study reported using contact rather than remote feeding methods. Unlike remote feeding, a greater proportion of contact feeders only had one regular donor for such purposes. Ambient, remote, and contact feeding are psychic vampire techniques, but in a sexual context, they usually involve a specific donor.

The more intimate sexual feeding methods included the ingestion of sexual fluids during oral sex, where semen is a substitute for blood; and sexual intercourse, either vanilla or tantric. Tantric sex, as practiced by non-vampires, has a spiritual essence, but vampires use the techniques to enhance the sexual energy available for feeding. With these methods there is not only the matter of safe sex, but particular to vampires is the taking in of energy during sex, so they reserve intimacy at this level for those donors who are "fluid bonded," which implies strict monogamy between these partners.

Each of these methods was often integrated with sang feeding (blood drinking, including ingestion of menstrual fluids) and non-sexual psi feeding (either ambient or via contact). Blood drinking usually involves cutting and takes place during or after sex. One researcher previously has described observing this act as "one of the most spiritual experiences that I have ever witnessed" (Thomas \& Williams, 2016, p. 91). Another intense practice almost exclusively occurring during sexual activity is "deep" or "core" feeding, initiated with a kiss to "draw out" sexual energy. Core feeding has the effect of heightening pleasure post-orgasm, often resulting in the donor falling asleep in order to recover from energy loss.

To improve sexual energy feeding, vampires reported that ingestion of sexual fluids (semen) was important but not necessarily so with blood, especially menstrual flow. During sexual activity, intimacy was reported as being somewhat important, as was foreplay to enhance the sexual feed. While vampire orgasm did not necessarily impact the success of a feed, participants reported that donor orgasm was important.

Sexual vampires often are assumed to suffer from either satyriasis (males) or nymphomania (females), and the sexual vampire label may be viewed as an excuse to have or want sex "all the time" (Browning, 2015b). While some interviewed vampires in this study admitted having high sex drives, most vampires reported engaging in sexual feeding more frequently than once per month but less than once per week. A similar number of participants reported sexual feeding more than once per week and at least once per day. Most vampires had sex for pleasure separate from sexual feeding, yet most participants claimed sex in conjunction with feeding was more enjoyable. For example, one vampire admitted she preferred "donation filled sex... In fact just the donation will do, you can keep the sex part."

Feeding in non-sexual ways affected the regularity of sexual feeding by generally decreasing the need for sex for the majority of respondents, but some reported an increase in sex drive. For example, one vampire explained that "Simply being a man, a gay 
man...there is usually not much of a surprise that I like a lot of sex...most of my partners like that." Clearly, a sex-positive approach is necessary to ensure all sexual vampires, regardless of gender or sexual orientation, can fulfill their feeding requirements without suffering judgments that are rooted in widespread sex-negativity.

\section{Committed Relationships}

According to participants we interviewed, sexual vampires are considered promiscuous, and some have been compared to sexual predators by other members of the vampire community. However, we found most vampires were in committed relationships with a high proportion being married. Most participants described their relationships as protective, nurturing and satisfying, claiming their partner(s) knew they were vampires and that they engaged in sexual feeding. A majority of participants sourced their sexual energy from within their present relationship, but this was not necessarily the only feeding source.

Feeding outside their primary relationships is a particular concern that sexual vampires face, with the emotional burden of trust underpinning all interactions with donors. When asked if feeding outside their relationships was an act of infidelity, most answered no, but as one participant noted, "unfortunately yes." For the most part, the definition of fidelity depended on the way the sexual energy was derived, so that if the feeding did not include contact with the donor, then as one participant believes, "... feeding off the flirtations of others wouldn't constitute infidelity in monogamous relationships." Several polyamorous vampires noted that relationship dynamics did not exclude the importance of honest disclosure between all partners involved. As one vampire explained, "it depends on the relationship. I'm poly, so no inherently, but if there's no communication or consent from all parties, then yes."

Sexual activity outside the relationship for non-feeding reasons was mostly answered with no, with all yes responses of such behavior being consensual. However, some respondents claimed that their partners display a higher level of mistrust in their relationship due to the very nature of being a sexual vampire.

\section{Donors}

A donor is (generally) a non-vampire who, for various reasons, provides blood and/or energy to real vampires. The sexual orientation of the vampire did not necessarily influence how they selected donors, but it proved important for feeding. Still, a third of the sample reported that their sexuality played no part in how they gained sexual energy from their donors. In ambient or remote feeding, sexual orientation plays no part in the flirtations; but by being responsible and having the donor's full knowledge and consent, they reduce the opportunity for unwanted sexual attention. In the process of arousal to generate sexual energy, the donor also benefits because, after the feed, they remain sexually excited for their own partner. 
Most vampires gained their sexual energy from donors using contact or sexually intimate feeding methods. During a feed, most vampires required only one donor at a time, with about a third requiring more than one donor simultaneously at the feed. A high proportion of sexual vampires claimed they did not have enough regular donors to satisfy their energy needs. Of those vampires who actively sought new donors, the reasons were mainly that their present donors did not supply enough energy or that occasionally they enjoyed the "thrill of the hunt." It was the "feel" of the donor's energy which attracted vampires in nearly all cases.

\section{Awakening}

The "awakening" of a real vampire is not an incident but more akin to a process, involving "the discovery and acceptance of our true nature as [vampires]... a period of personal struggle that is marked by emotional and metabolic changes, increased sensitivities and intuitive awareness..." (Madame X, personal communication, May 26, 2016). Vampires believe that awakening is not a choice, much like puberty, where physiological changes occur with sexual development. But because awakening also involves self-acceptance, not all vampires become aware of their nature automatically. The data revealed that although a majority of vampires in our study are chronic, the periods of self-identification do not necessarily correlate with age.

One of the serious issues discussed by sexual vampires in this study is the education of young vampires who are awakening. They are considered vulnerable if they are left to experiment on their own with feeding methods, where for sexual vampires this includes not only coming to terms with their sexuality during puberty but the need for energy produced during sexual contact, which can prove confusing. Any physical contact with their peers can derive an energy reward, such that the young vampire quickly learns more intimate interactions produce more satisfying energy. Without guidance to explain the source of these energy sensations, they run the risk of an "unsafe" sex practice peculiar to sexual vampires; i.e., that sex is not "food" but via intimacy they can gain more than just energy and experience the full pleasure of sex.

Education for young vampires concerning feeding methods is a controversial subject within the vampire community, particularly for those engaged in sexual feeding. Vampires in our study reported they started seeking sexual pleasure between the ages 1218 , but in rare cases this occurred earlier. From an early age, children are taught sexual acts are wrong, or "bad," thus cultivating shame and making it difficult for sexual vampires to feed void of guilt. Many sexual vampires complain that they still suffer the feeling they are "sluts," where the term has no gender affiliations. A sex-positive approach could assist vampires in understanding that any sexual topic and issue can and should be discussed in an open and mature way. 


\section{Early "Causes"}

There is also the false belief that sexual vampirism is somehow "caused" by sexual trauma, particularly childhood sexual abuse (CSA) (Aaron, 2012). While we did not directly investigate this in our survey, discussions on sexual behavior and history indicate CSA does not seem to influence sexual vampire nature. Sexual vampires do not exhibit sexual inhibitions, fear sex, or suffer a lack of interest in sex. Sexual dysfunction is not discussed, no matter the gender of the vampire. While it might be argued that sexual vampires are sexually compulsive, they are very aware of why they seek sexual contact, thus negating the charge that they suffer from sexual behavior problems. Compulsive masturbation and performance issues do not seem to plague sexual vampires. Findings suggest that pornography, while interesting to some, did not form a particular fascination, and it certainly was not a dependence issue. This is not to say sexual vampires have never suffered CSA, only that if they were such victims, they do not display common sexual problems associated with CSA as adults.

\section{$B D S M$}

Sexual vampires are more likely than the general population to indulge in kink activities, and vampires have a long history of involvement with the BDSM subculture (Laycock, 2009a). The motivation for vampires indulging in BDSM extends beyond mere pleasure to include sexual feeding. Feeding may also include sang feeding, where caning the donor produces blood for the vampire to lick from the donor's skin.

Research to explain the attraction for and participation in BDSM is varied (Taylor \& Ussher, 2001; Weinberg, 2006; Williams, 2013). For sexual vampires, one reason for kink is to obtain the sexual energy generated during the scene. In our survey, all vampires who practiced BDSM (about three-quarters of our total sample) fed during the scene, with about a third engaged in BDSM activities solely or primarily for feeding. The rest also sought BDSM play for non-feeding pleasure.

In our investigation of feeding practices, we did not examine the pleasure derived from non-feeding BDSM, which may or may not be primarily sexually motivated (Sagarin, et al. 2015; Williams, et al. 2016). Interest in BDSM is associated with power exchange, psychological factors, and a spiritual practice called "Sex Magic" involving play with cutting. In Sex Magic, "....when you open up the body by cutting...there is often a genuine opening of the mind, emotions and spirit as well..." (Easton \& Hardy, 2001, p. 127). Vampires practice Sex Magic, but while deeply spiritual in nature, their rituals appear to have strong sexual overtones, in that the focus is for controlling orgasm, which is often necessary for sexual feeding. While the intentions for non-vampires vary widely, sexual vampires almost certainly aim to influence any working to maximize the energy benefits. Sex Magic is often associated with "Blood Magic," where the blood is symbolic so only a drop is necessary for the ritual. How Sex and Blood Magic works in BDSM is a 
matter of personal choice, as not all vampires use it in conjunction with BDSM. Whether non-vampires will adopt vampire versions of Sex Magic remains conjectural. Despite recent assessments of BDSM per se as non-pathological (Weinberg, 2006; Williams, 2013, Williams, et al. 2016), a sex-positive view may be useful for potential donors when participation in BDSM is associated with vampirism.

According to our data, feeding occurred in progressions of the scene from the build-up, involvement, and climax, but did not occur within the period of aftercare. Most feeding occurred during scene involvement. Important reasons given for not feeding during the scene included respect for the "bottom" (submissive) and the necessity for "tops" (dominants) to adhere to BDSM rules of SSC (safe, sane, and consensual).

Respect for the bottom extended to aftercare, and as one vampire explained, "that is a time for comfort and winding down; I respect them by not feeding...it could alter their mindset, ruining everything worked for during the scene."

In the choice of role during BDSM activities, the majority of vampires answered with a preference for switching (topping and bottoming), but approximately equal numbers of the rest preferred either topping (dominance) or bottoming (submission). This result was unexpected, as vampires are usually considered dominant, using the role of topping to focus the energy of the feed. But as one participant observed, there are "a lot of vampires who are primarily sexual submissives and masochists... (they) get energy by acting as lightning rods, grounding the massive energy their top puts into the dominance and sadism."

\section{Feeding Necessity}

Vampires believe that their specific risks extend beyond the physical, but a unique issue involves feeding from a donor without the "right energy." The significance of "right energy" was not directly explored in our study; however, when asked about the consequences of not feeding at all or not feeding regularly, the effects reported were mainly physical and emotional, including lethargy/fatigue, various illnesses, headaches/migraines, body pains, eating problems, sensitivities, depression/anxiety, mood swings, and increased sexual desire. These symptoms were not dependent on the source of energy, which for some vampires included blood and psi energy. That sexual vampires should treat or avoid these complications seems to form a strong motivation for their sexual feeding. The necessity for a sex-positive understanding of sexual vampires becomes important so that their sexual behavior is not misinterpreted as part of their health issues and considered a problem. The need to feed might also be a motivation, as one participant commented, "Sexual vampires need to know how to keep fed, so that they don't get too energetically hungry and engage in any risky sexual behavior."

\section{Conclusion}


Our primary goal for this study was to examine possible motivations of vampires who claim to require sexually stimulating activities in order to feed. While considering motivations for sexual experiences, many find that the most important factor is indeed the personal choice to seek sex (or avoid it), yet the claims of sexual vampires suggest that they need some form of sexual activity in order to optimize their health. We hoped to investigate the necessity of sex for sustaining the energy of sexual vampires, but the data revealed that this is more complex than expected; for example, vampires seeking sex primarily for ordinary pleasure or for preferring sex for the purpose of feeding. We found that this little-known sexual minority faces many complex issues, not only those arising from their condition as real vampires but in particular from complications arising from the apparent need to feed sexually. More research exploring these issues is warranted. A positive sexuality approach that emphasizes empowerment, self-determination, unique sexuality, and human diversity is needed for sexual vampires, as well as other minority communities.

Aaron, M. (2012). The pathways of problematic sexual behavior: A literature review of factors affecting adult sexual behavior in survivors of childhood sexual abuse. Sexual Addiction \& Compulsivity. 19, 199-218. Retrieved from http://www.drmichaelaaronnyc.com/tho ughts-working-adult-survivorschildhood-sexual-trauma-csa/

Aaron, M. (2016). Are you aware of your therapist's biases? You should be. Psychology Today. Retrieved from https://www.psychologytoday.com/blog /standard-deviations/201606/are-youaware-your-____ therapist's-biases-youshould-be

Atlanta Vampire Alliance. (2007). The vampire and energy work research survey: An introspective examination of the real vampire community. Atlanta, GA: Author

Belanger, M. (2004). The Psychic Vampire Codex. Boston, MA: Weiser Books

Browning, J. E. (Ed.) (2014). Interviews with the Vampires. In M. Summers, The vampire in Europe: A critical edition. Berkeley, CA: Apocryphile Press

Browning, J. E. (2015a). Life Among the Vampires. The Atlantic. Retrieved from http://www.theatlantic.com/health/archi ve/2015/10/life-among-thevampires/413446/

Browning, J. E. (2015b). The real vampires of New Orleans and Buffalo: A research note towards comparative ethnography. Palgrave Communications

Easton, D. \& Hardy, J. W. (2001). The new bottoming book. Emeryville, CA: Greenery Press.

Gray, D. (2016 February 18). What have you heard [Web log post]. Retrieved from

https://thegraveyardpress.wordpress.co m/2016/02/18/what-have-you-heard/

Laycock, J. (2009a). Vampires Today: The truth about modern vampirism. Westport, CT: Praeger

Laycock, J. (2009b). Modern vampires: Your neighbors and spouses. Religion Dispatches. (May 28, 2009). Retrieved from http://religiondispatches.org/modernvampires-your-neighbors-and-spouses/

Laycock, J. (2010). Real vampires as an identity group: Analyzing the causes and effects of an introspective survey by the vampire community. Nova Religio: The Journal of Alternative and Emergent Religions, 14 (1), 4-23

Laycock, J. (2016). Reply to "Do we always practice what we preach? Real vampires' fears of coming out of the coffin to social workers and helping professionals." Critical Social Work, 17 (2), 83-89

Sagarin, B. J., Lee, E. M. \& Klement, K. R. (2015). Sadomasochism without sex? Exploring the parallels between BDSM 
and rituals. Journal of Positive

Sexuality, 1, 50-55

Taylor, G. \& Ussher, J. (2001). Making sense of S\&M: A discourse analytic account. Sexualities, 4, 293-314. Retrieved from http://sex.sagepub.com/content/4/3/293

Thomas, J. N. \& Williams, D. J. (2016). Getting off on sex research: A methodological commentary on the sexual desires of sex researchers. Sexualities, 19 (1 2), 83-97

Williams, D. J. (2008). Contemporary vampires and (blood-red) leisure: Should we be afraid of the dark? Leisure/Loisir, 32, 513-539

Williams, D. J. (2009). Deviant leisure: Rethinking "the good, the bad, and the ugly." Leisure Sciences, 31, 207-213

Williams, D. J. (2013). Social work, BDSM, and vampires: Toward understanding and empowering people with non-traditional identities. Canadian Social Work, 15, 10-24
Williams, D. J, \& Browning, J. E. (2016).

Looking inside the coffin: An overview of contemporary human vampirism and its relevance for forensics professionals. In M. Arntfield \& M. Danesi (Eds.), The Criminal Humanities: An Introduction (Criminal Humanities \& Forensic Semiotics). (pp. 117-134) New York: Peter Lang Publishing

Williams, D. J. \& Prior, E. E. (2015). Do we always practice what we preach? Real vampires' fears of coming out of the coffin to social workers and helping professionals. Critical Social Work, 16 (1) 79-92

Williams, D. J., Prior, E. E., \& Wegner, J. (2013). Resolving social problems associated with sexuality: Can a "sexpositive" approach help?. Social Work, 58, 273-276

Williams, D. J., Prior, E. E., Alvarado, T., Thomas, J. N., \& Christensen, M. C. (2016). Is bondage and discipline, dominance and submission and sadomasochism recreational leisure? A descriptive exploratory investigation. Journal of Sexual Medicine, 13, 10911094

Williams, D. J., Thomas, J. N., Prior, E. E., \& Walters, W. (2015). Introducing a multidisciplinary framework of positive sexuality. Journal of Positive Sexuality, $1,6-11$ 